\title{
Paracrine regulation of apoptosis by steroid hormones in the male and female reproductive system
}

T Kurita', YZ Wang ${ }^{1}$, AA Donjacour ${ }^{1}$, C Zhao', JP Lydon ${ }^{3}$, BW O'Malley ${ }^{3}$, JT Isaacs ${ }^{4}$, R Dahiya ${ }^{2}$ and GR Cunha ${ }^{\star, 1,2}$

${ }^{1}$ Department of Anatomy, University of California, San Francisco, California, CA 94143, USA

2 Department of Urology, University of California, San Francisco, California, CA 94143, USA

${ }^{3}$ Department of Molecular and Cell Biology, Baylor College of Medicine, Houston, Texas, TX 77030, USA

${ }^{4}$ Department of Oncology, Johns Hopkins University School of Medicine, Baltimore, Maryland, MO 21231, USA

* Corresponding author: GR Cunha, Department of Anatomy, University of California San Francisco, San Francisco, California, CA 94143, USA

Tel:(415) 476-4140; Fax:(415) 502-2270; E-mail: gcunha@itsa.ucsf.edu

Received 7.3.00; revised 30.8.00; accepted 11.10.00

Edited by FD Miller

\section{Abstract}

In males, androgens are essential in maintaining the integrity of the prostate. Androgen-ablation induces apoptosis of the prostatic epithelium. In females, ovariectomy induces apoptosis in uterine epithelium while progesterone inhibits this process. The objective of this study was to determine whether androgen and progesterone inhibit apoptosis, respectively, in mouse prostatic and uterine epithelia via steroid receptors in the epithelium or in the stroma. To address this question, prostatic tissue recombinants were prepared with rat urogenital sinus mesenchyme plus bladder epithelium from wild-type or testicular feminization mutant ( $\mathrm{Tfm})$ mice. Thus, prostatic tissue was generated having androgen receptor (AR) in both epithelium and stroma or in the stroma only. Castration of hosts induced apoptosis in the AR-negative Tfm prostatic epithelium with an epithelial apoptotic index virtually identical to prostatic tissue recombinants containing wild-type epithelium. Moreover, this castration-induced prostatic epithelial apoptosis was blocked by testosterone and dihydrotestosterone in both wild-type and Tfm prostatic tissue recombinants. Likewise, uterine tissue recombinants were prepared in which epithelium and/or stroma was devoid of progesterone receptor (PR) by using uterine epithelium and stroma of wild-type and PR knockout mice. Progesterone inhibited uterine epithelial apoptosis only in tissue recombinants prepared with PR-positive stroma. The PR status of the epithelium did not affect epithelial apoptotic index. Therefore, the apoptosis in prostatic and uterine epithelia is regulated by androgen and progesterone via stromal $A R$ and $P R$, respectively. In both cases, epithelial AR or PR is not required for hormonal regulation of epithelial apoptosis in prostatic and uterine epithelium. Cell Death and Differentiation (2001) 8, 192-200.
Keywords: mouse; epithelial-stromal tissue interaction; androgen; testosterone; dihydrotestosterone (DHT); androgen receptor

Abbreviations: AR, androgen receptor; DHT, dihydrotestosterone; $\mathrm{E}_{2}$, 17- $\beta$ estradiol; $\mathrm{PR}$, progesterone receptor; $\mathrm{PRKO}$, progesterone receptor knockout; $\mathrm{P}_{4}$, progesterone; $\mathrm{T}$, testosterone; Tfm, testicular feminization mutant; wt, wild-type

\section{Introduction}

Both male and female reproductive tissues show dramatic growth and regression during reproductive cycles. Steroid hormones, androgen in males and 17- $\beta$ estradiol $\left(E_{2}\right)$ and progesterone $\left(\mathrm{P}_{4}\right)$ in females, are key regulators of these growth/regression cycles. Studies of epithelial apoptosis in male $^{1}$ and female, ${ }^{2,3}$ reproductive tracts have demonstrated that epithelial apoptosis in steroid target organs is under the control of steroid hormones. In the male, the prostate is dependent on androgens for growth, function and maintenance of tissue architecture. ${ }^{4}$ Androgen deprivation elicited by physiological or chemical castration induces apoptosis in prostatic epithelium of rats and mice. In the rodent ventral prostate, epithelial apoptosis reaches its maximum 3 days after castration. ${ }^{4,5}$ In females, apoptosis plays an important role in regulating functions in the reproductive tract, and is regulated by two ovarian steroid hormones, $E_{2}$ and $P_{4}$. $E_{2}$ is mitogenic for uterine epithelium, while $\mathrm{P}_{4}$ inhibits proliferation and apoptosis of uterine epithelium. ${ }^{6,7}$ Increased systemic levels of $E_{2}$ at the proestrus/estrus-phases induces growth of uterine tissue. The integrity of the uterus is maintained in part by $\mathrm{P}_{4}$, which prevents cell death. If pregnancy is not established, the level of $\mathrm{P}_{4}$ drops, and uterine epithelial tissue regresses via apoptosis. ${ }^{8}$ This prolifertive/apoptotic cycle in uterine epithelium can be mimicked in ovariectomized mice by a hormone treatment protocol with $\mathrm{P}_{4}$ and $\mathrm{E}_{2 .}$.

Steroid hormone action is mediated via nuclear receptor proteins, which function as ligand modulated transcription factors. ${ }^{9}$ Androgen and $\mathrm{P}_{4}$ signals are mediated through the androgen receptor (AR) and progesterone receptor (PR), respectively. Many genes are regulated by steroid hormones, and it has been tacitly assumed that hormonal effects on a cell are mediated through receptors in the responding cell. However, hormone target organs such as the prostate and uterus express steroid receptors in both epithelial and stromal cells. ${ }^{10,11}$ The importance of paracrine mechanisms in steroid hormone action in male and female reproductive tracts has been well established. For example, proliferation of normal epithelial cells induced by steroids in male and female reproductive tracts appears to be regulated via paracrine mediators produced by stromal cells. The idea that epithelial proliferation is 
regulated in vivo by paracrine mechanisms is based upon several lines of evidence: (a) $E_{2}$ and testosterone (T) are not mitogenic when applied to primary cultures of normal target epithelial cells. ${ }^{12,13}$ (b) Mitogenicity of $E_{2}$ for uterine and vaginal epithelia is reconstituted when cultured epithelial cells are recombined with stroma, and the tissue recombinants are grafted in vivo. ${ }^{14}$ (c) Androgen stimulates proliferation of Tfm prostatic epithelium, which is devoid of functional $A R$, in prostatic tissue recombinants made with $\mathrm{Tfm}$ epithelium plus wild-type stroma. ${ }^{15}$ (d) Uterine and vaginal tissue recombinants composed of $E R \alpha$-negative epithelium derived from $\mathrm{ER} \alpha$ knockout mice and $\mathrm{ER} \alpha$ positive wild-type stroma demonstrate conclusively that mitogenicity of estrogen in normal uterine and vaginal epithelia is dependent upon $\mathrm{ER} \alpha$ in the stroma in vivo. ${ }^{16,17}$ Epithelial $E R \alpha$ is neither necessary or sufficient for the mitogenicity of estrogen in normal target epithelial cells in vivo. Similar evidence has been demonstrated for antimitogenic effect of $\mathrm{P}_{4}$ for uterine epithelium. ${ }^{18} \mathrm{P}_{4}$ inhibits $\mathrm{E}_{2}$-induced uterine epithelial DNA-synthesis in PR-negative epithelium from PRKO mice when the epithelial cells are combined with PR-positive uterine stroma from wild-type mice. In contrast, $\mathrm{P}_{4}$ does not block $\mathrm{E}_{2}$-induced DNAsynthesis in PR-positive uterine epithelium combined with PR-negative uterine stroma. ${ }^{18}$ Thus, in all cases epithelial steroid receptors are not required for the regulation of proliferation of normal epithelial cells in vivo. Paracrine mechanisms are also involved in the regulation of lactoferrin expression by $\mathrm{E}_{2}{ }^{19}$ and $\mathrm{P}_{4}{ }^{20}$ in uterine epithelium, and regulation of uterine epithelial $P R$ by $E_{2}{ }^{21}$ and $\mathrm{P}_{4} \cdot{ }^{20}$ These facts raise the possibility that the apoptosis of epithelial cells in male and female reproductive tracts may also be regulated by steroid hormones through paracrine mechanisms.

In this study we report a paracrine mechanism for regulation of apoptosis in prostatic and uterine epithelia. To study the respective roles of epithelial versus stromal steroid receptors in the anti-apoptotic action of androgen on prostatic epithelium and $\mathrm{P}_{4}$ on uterine epithelium, tissue recombination techniques were utilized. Since stromal AR is essential for the development of prostate, ${ }^{22}$ we could not make prostatic tissue recombinants with AR-negative stroma. To demonstrate whether epithelial AR is required for the regulation of prostatic epithelial apoptosis, bladder epithelium (BLE) was combined with urogenital sinus mesenchyme (UGM) which result in prostatic induction. ${ }^{23}$ If the BLE is derived from wild-type mice, the resultant induced prostatic epithelium expresses many markers indicative normal prostatic epithelium including prostatic specific secretory proteins, ${ }^{24} \mathrm{Nkx3} .1^{25}$ and AR. ${ }^{23}$ If $\mathrm{Tfm}$ bladder is combined with wild-type UGM prostatic ducts also form and the induced Tfm prostatic epithelium expresses $\mathrm{Nkx3} .1^{25}$ and proliferates in response to androgen even though the Tfm prostatic epithelium does not express prostatic secretory proteins due to lack of epithelial AR. ${ }^{15,24}$ To determine the role of stromal versus epithelial AR in prostatic epithelial apoptosis, prostatic tissue recombinants were prepared with BLE of $\mathrm{Tfm}$ and wt mice combined with rat UGM. The induced prostatic tissue expressed $A R$ in both its epithelium (E) and stroma (S) in wt-S+wt-E tissue recombinants, or only in stroma but not the epithelium in wt-S+Tfm-E tissue recombinants. Likewise, to determine whether $\mathrm{P}_{4}$ inhibits uterine epithelial apoptosis via epithelial versus stromal PR, 4 types of tissue recombinants were prepared with uterine stroma (S) and epithelium (E) from wild-type (wt) and PR knockout (PRKO) mice: wt-S+wt-E, wt-S+PRKO-E, PRKO-S+wt-E and PRKO-S+PRKO-E

\section{Results}

\section{Prostatic epithelial apoptosis induced by androgen-withdrawal in androgen receptor null prostatic epithelium}

In intact male mice, very few apoptotic cells were observed in the epithelium of the ventral (Figure 1c) and dorsolateral lobes of prostate, and the apoptotic index (derived from terminal deoxynucleotidyltransferase dUTP nick end labeling [TUNEL] stained specimens) was low in the ventral prostate (VP) and
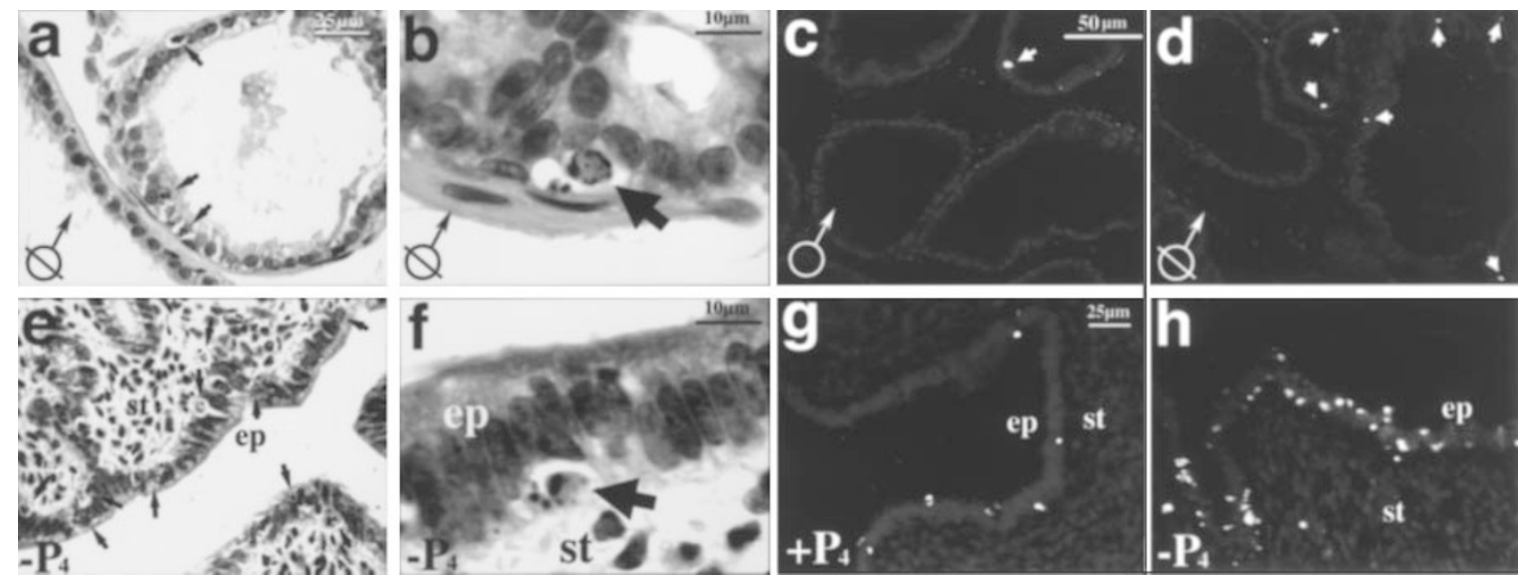

Figure 1 Apoptosis in mouse prostate and uterus. Ventral prostate $(\mathbf{a}-\mathbf{d})$ of castrated $(\mathbf{a}, \mathbf{b}, \mathbf{d})$ and intact $(\mathbf{c})$ mice. Uterus $(\mathbf{e}-\mathbf{h})$ of $\mathrm{P}_{4}$-treated $(\mathbf{g})$ and oil-treated (d,e,f) mice. Apoptotic cells (arrows) were detected by H\&E staining (a,b,e,f) and TUNEL staining (c,d,g,h). ep, epithelium; st, stroma 
dorsolateral prostate (DLP) (Table 1). Castration induced apoptosis of prostatic epithelium in both VP (Figure 1a,b,d) and DLP (not shown). At 3 days after castration, the epithelial apoptotic index significantly increased from that of intact mice in both VP and DLP with epithelial apoptotic index being significantly higher in VP than in DLP (Table 1). Rat VP is widely used as a model system for studying mechanisms of epithelial apoptosis. Epithelial apoptotic index in rat and mouse VP and DLP was also compared by counting positive cells for TUNEL staining. In both rat and mouse, epithelial apoptotic index was exceedingly low in intact animals, increased at 3 days after castration, and was significantly higher in VP than DLP following castration. In both VP and DLP, epithelial apoptotic index at 3 days after castration was significantly higher in rat than mouse (Table 1).

Prostatic tissue recombinants were prepared with rat urogenital sinus mesenchyme (rUGM) plus mouse bladder epithelium (mBLE) from wild-type (wt) or Tfm mice. The rUGM+mBLE tissue recombinants were grown under the kidney capsule of male athymic nude mice for 1 month (see Figure $6 \mathrm{~A}$ for treatment protocol). After 1 month, both types of prostatic tissue recombinants developed normally and showed comparable prostatic histology as reported previously ${ }^{23}$ (Figure 2a,b). AR was detected in the wild-type rat stroma whether wt-mBLE or Tfm-mBLE was used to prepare the tissue recombinants (Figure 2a,b, arrows). AR was detected in the epithelium of rUGM+wt-mBLE tissue recombinants (Figure 2a) but not in the epithelium of rUGM+Tfm-mBLE tissue recombinants (Figure 2b). In intact hosts, epithelial apoptotic indices of both rUGM+wt-mBLE and rUGM+Tfm-mBLE prostatic tissue recombinants were equally low; there was no significant difference in epithelial apoptotic index in rUGM+wt-mBLE and rUGM+Tfm-mBLE tissue recombinants (Figure $4 A, a$ ). Three days after castration, many epithelial cells positive for TUNEL staining were detected in epithelium of both wt-mBLE and Tfm-mBLE prostatic tissue recombinants (Figure $3 a, b$ ). In castrated hosts the epithelial apoptotic indices of both rUGM+wt-mBLE and rUGM+Tfm-mBLE prostatic tissue recombinants (Figure $4 A, b)$ increased significantly relative to tissue recombinants in intact hosts (Figure 4a). In castrated hosts, the difference in epithelial apoptotic index between rUGM+wt-mBLE and rUGM+Tfm-mBLE prostatic tissue recombinants was not significant. In addition to the androgen, orchiectomy could change levels of other hormones, such as estrogen. To confirm that the castration induced epithelial apoptosis in the

Table 1 Epithelial apoptotic index in mouse and rat VP and DLP

\begin{tabular}{lccc}
\hline \multirow{2}{*}{ Species } & & \multicolumn{2}{c}{ Apoptotic index (\%) } \\
Rat & Lobe & Intact & Castrated \\
\multirow{3}{*}{ Mouse } & VP & $0.43 \pm 0.23^{\mathrm{a}}$ & $4.47 \pm 0.66^{\mathrm{b}}$ \\
& DLP & $0.45 \pm 0.25^{\mathrm{a}}$ & $2.32 \pm 0.49^{\mathrm{c}}$ \\
& VP & $0.49 \pm 0.28^{\mathrm{a}}$ & $2.49 \pm 0.49^{\mathrm{c}}$ \\
& DLP & $0.07 \pm 0.05^{\mathrm{d}}$ & $0.23 \pm 0.15^{\mathrm{a}}$ \\
\hline
\end{tabular}

Mature adult male rats and mice (approximately 3 month old) were castrated. Three days after castration, VP and DLP were collected. Positive and negative cells for TUNEL staining were counted to determine epithelial apoptotic indices. Value with different letter designation $\left({ }^{a-d}\right)$ are all significantly different $(P<0.05)$ in following order, ${ }^{d}<^{a}<{ }^{c}<{ }^{b}$ prostatic tissue recombinants was due to a decrease in the androgen level, the host nude mice were given an androgen pellet ( $20 \mathrm{mg}$ of T or DHT), and then castrated on 3 days after the pellet implantation. Both T and DHT blocked castrationinduced epithelial apoptosis in both rUGM+wt-mBLE and rUGM+Tfm-mBLE prostatic tissue recombinants (Figure 3 and 4). Thus, differences in apoptotic indices were not statistically different in T-pellet/castration, DHT-pellet/castration and intact groups in both rUGM+wt-mBLE and rUGM+Tfm-mBLE tissue recombinants (Figure 4a). These results clearly showed that androgen maintains integrity of prostatic epithelial tissue via stromal AR. Epithelial AR is not involved in this process. Since DHT cannot be aromatized to estrogenic compounds, a role of estrogens in this process can be excluded.

\section{Inhibition of apoptosis by $\mathrm{P}_{\mathbf{4}}$ in PR null uterine luminal epithelial apoptosis}

Uterine tissue recombinants (wt-S+wt-E, wt-S+PRKO-E, PRKO-S+wt-E and PRKO-S+PRKO-E) were grafted under the renal capsule of adult female athymic nude mice, and then all hosts received hormone treatments on the schedule shown in Figure 6B. To establish a baseline, we first examined uterine epithelial apoptosis in the host's uteri. Twenty-four hours after the last injection, many apoptotic cells were detected in uterine luminal epithelium of oil-treated hosts as judged by both apoptotic bodies observed in H\&E stained slides (Figure 1e,f) and by TUNEL staining for in situ DNA fragmentation (Figure 1h). In contrast, very few apoptotic bodies and TUNEL stained epithelial cells were detected in uterine luminal epithelium of $\mathrm{P}_{4}$-treated hosts (Figure $1 \mathrm{~g}$ ). $\mathrm{P}_{4^{-}}$ treatment significantly reduced the apoptotic index in uterine luminal epithelium of host mice from $15.91 \pm 0.572 \%$ to $4.46 \pm 0.951 \%(P<0.001)$. Thus, for the uteri of host nude mice, $\mathrm{P}_{4}$ was anti-apoptotic as described previously. ${ }^{26}$

In all uterine tissue recombinants, the tissue types (PRpositive (wild-type) or PR-negative (PRKO)) were confirmed with PR-immunohistochemistry. Only tissues of wild-type mouse origin stained for PR. This is particularly evident in heterotypic tissue recombinants (wt-S+PRKO-E and PRKOS+wt-E) (stroma in Figure 2d and epithelium in Figure 2e). In all four types of uterine tissue recombinants, apoptotic index of oil-treated $\left(-\mathrm{P}_{4}\right)$ group was high $(14-18 \%)$ and similar to that of the host's uterine epithelium (Figure 4B). $\mathrm{P}_{4}$-treatment inhibited uterine epithelial apoptosis only in tissue recombinants prepared with wt-S (wt-S+wt-E and wt$S+P R K O-E$, Figure 3e,f, respectively). Thus, in wt-S+wt-E and wt-S+PRKO-E tissue recombinants, epithelial apoptotic index was significantly lower in the $\mathrm{P}_{4}$-treated group $\left(+\mathrm{P}_{4}\right)$ than that of the oil-treated group $\left(-\mathrm{P}_{4}\right)($ Figure $4 \mathrm{Bc})$. The presence or absence of $P R$ in the epithelium did not affect its response to $P_{4}$. In contrast, $P_{4}$-treatment did not inhibit apoptosis in tissue recombinants lacking $P R$ in the stroma (PRKO-S+wt-E and PRKO-S+PRKO-E, Figure 3g,h, respectively). Thus, in response to $\mathrm{P}_{4}$ epithelial apoptotic index in PRKO-S+wt-E and PRKO-S+PRKO-E tissue recombinants was significantly higher (Figure 4Bd) than that of wt-S+wt-E and wt-S+PRKO-E uterine tissue recombinants in the $\mathrm{P}_{4}$-treated host (Figure $4 \mathrm{BC}$ ). 


\section{prostatic tissue recombinants}

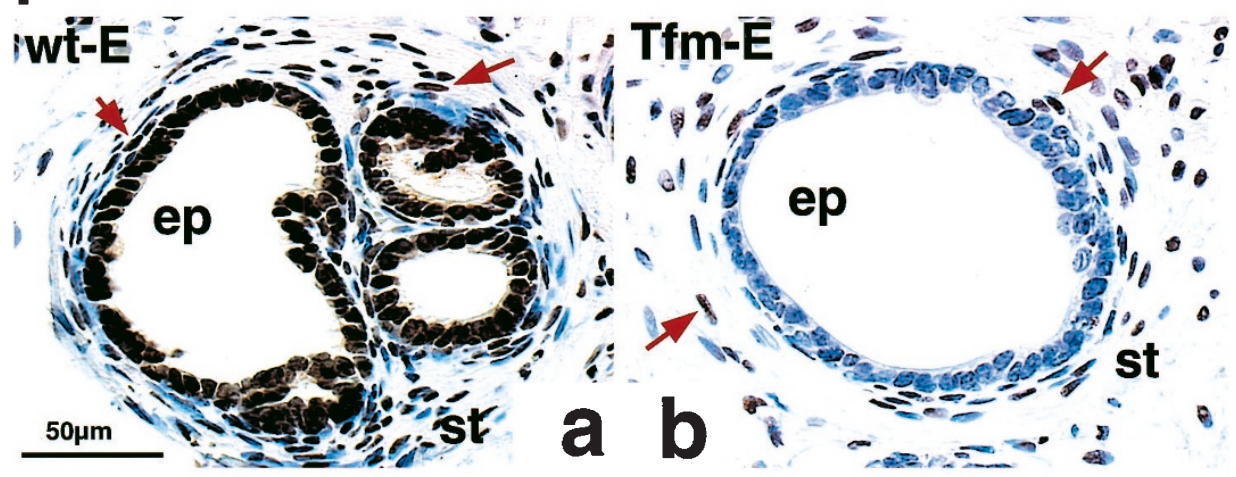

\section{uterine tissue recombinant}

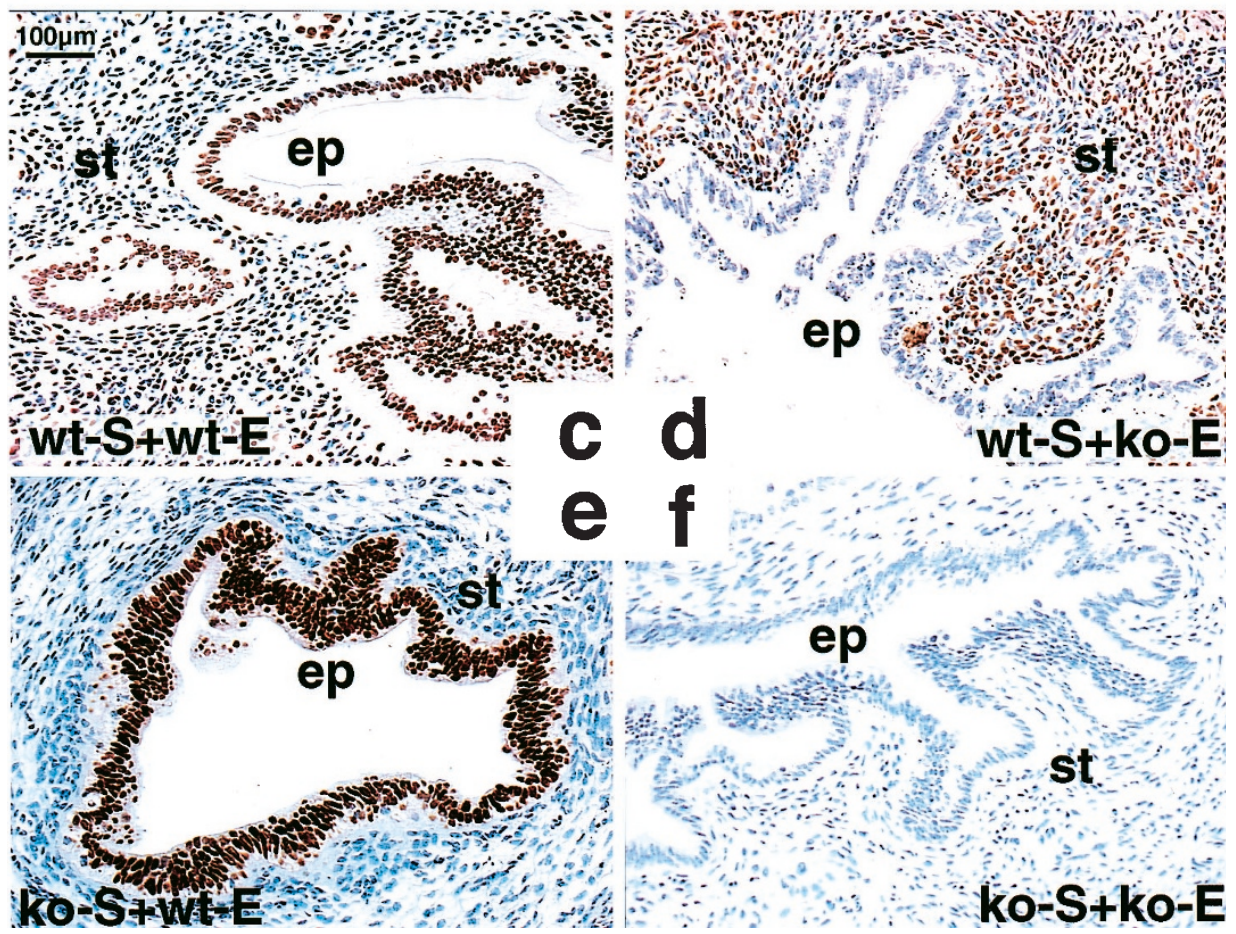

Figure 2 Immunohistochemistry for AR and PR in uterine and prostatic tissue recombinants. ep, epithelium; st, stroma. AR-immunohistochemistry in prostatic tissue recombinants $(\mathbf{a}, \mathbf{b})$. Tissue recombinants were prepared with rat urogenital sinus mesenchyme (rUGM) and bladder epithelium (BLE) of wild-type (wt) or Tfm mice (m). In rUGM+wt-mBLE recombinants (a), AR-positive cells were detected in both epithelium and stroma (arrows). In contrast, AR-positive cells were detected only in stroma (arrows) of rUGM+Tfm-mBLE tissue recombinants (b). PR-immunohistochemistry in uterine tissue recombinants prepared with wild-type and PRKO tissues $(\mathbf{c}-\mathbf{f})$. Tissue recombinants were prepared with uterine epithelium (E) and stroma (S) from wild-type (wt) and PR knockout (ko) mice. In wt-S+wt-E tissue recombinants (c), positive nuclear staining for PR was detected in both epithelium and stroma. In contrast, both epithelium and stroma were negative for PR in koS+ko-E tissue recombinants (f). In wt-S+ko-E (d) and ko-S+wt-E (e) tissue recombinants, only wt-S or wt-E is positive for PR, respectively

\section{Discussion}

This study clearly demonstrated that steroid hormones regulate survival of epithelial cells via stromal steroid receptors in both prostatic and uterine tissue. Thus, androgen and progesterone regulate apoptosis in prostatic and uterine epithelia through paracrine mechanisms mediated by hormone receptors in the stroma. Paracrine regulation of epithelial cell death has been proposed in various models of development. For example, regression of embryonic mammary epithelial cells in male mice is induced by androgen through a paracrine mechanism mediated via $\mathrm{AR}$ in mammary mesenchyme. ${ }^{27}$ Likewise, apoptosis of Müllerian epithelium is induced by Müllerian inhibitory substance presumably via receptors in surrounding mesenchyme. ${ }^{28}$ In the case of mammary gland and Müllerian duct, the epithelial receptors for the hormones triggering epithelial apoptosis were not detected. In contrast, in prostate and uterus both the epithelium and stroma express receptors for the steroid hormones regulating epithelial apoptosis. Never- 


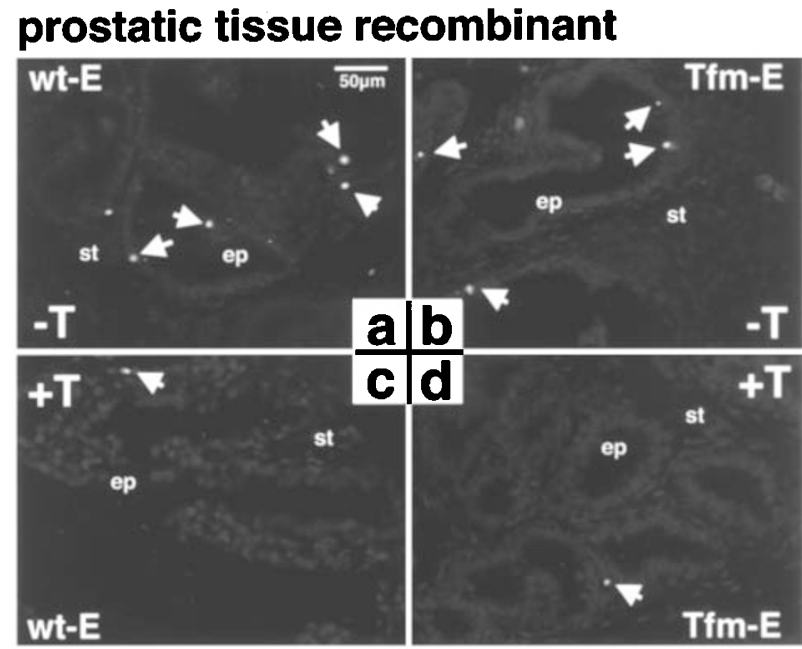

\section{uterine tissue recombinant}

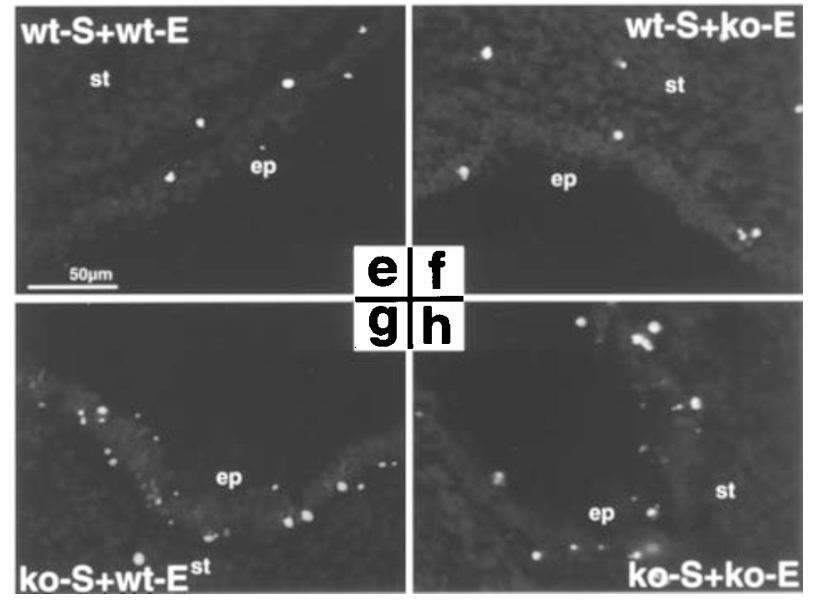

Figure 3 Detection of apoptotic cells by in situ DNA fragmentation in prostatic and uterine tissue recombinants. rUGM+wt-mBLE (wt-E) $(\mathbf{a}, \mathbf{c})$ and rUGM+Tfm-mBLE (Tfm-E) (b,d) prostatic tissue recombinants in hosts 3 days post castration with $(\mathbf{c}, \mathbf{d})$ and without $(\mathbf{a}, \mathbf{b}) 20 \mathrm{mg}$ T-pellet (see Figure $6 \mathrm{~A}$ for treatment protocol). Uterine tissue recombinants prepared with wild-type (wt) and PRKO (ko) tissues growing in $\mathrm{P}_{4}$-treated hosts. Wt-S+wt-E (e), wt-S+ko-E (f), ko-S+wt-E (g) and ko-S+ko-E (h). All hosts were received $2 \mathrm{mg}$ of $\mathrm{P}_{4}$ injection daily following $E_{2}$ treatment (see Figure $6 B$ for treatment protocol)

theless, this study has clearly shown that epithelial steroid receptors are not involved in regulation of prostatic or uterine epithelial apoptosis induced by the withdrawal or the absence of androgen and progesterone, respectively. Hence, epithelial $A R$ and $P R$ are not required to directly regulate transcription of intracellular effectors for apoptosis in the mouse prostatic and uterine epithelial cells. This implies that some form of communication between the stroma and epithelium is required to elicit apoptosis in the epithelium.

There are two possible mechanisms by which stromal cells may control apoptosis of epithelial cells (Figure 5). In presence of steroid hormone, stroma may produce survival factors for epithelium (Figure 5A). Withdrawal of steroid hormones would down-regulate production of the survival factors and thus trigger apoptosis of epithelial cells (Figure $\left.5 A^{\prime}\right)$. In some cells, cell death can be induced by withdrawal of peptide survival factors, such as epidermal growth factor (EGF). ${ }^{29}$ In prostate, androgens modify expression levels of members of EGF family ligand and receptors. ${ }^{30-32}$ In uterus, $E_{2}$ and $P_{4}$ regulate expression of peptide growth factors, such as members of EGF family, ${ }^{33,34}$ insulin-like growth factors (IGFs) ${ }^{35-37}$ and fibroblast growth factors (FGFs). ${ }^{38,39}$ Such peptide growth factors are good candidates for the survival factors for prostatic and uterine epithelium.

Alternatively, in response to decreased steroid levels stroma may produce death signals, which induce epithelial apoptosis (Figure 5B). In the prostate castration induces expression of several secreted molecules such as IGF binding proteins (IGFBPs). ${ }^{40}$ In the uterus, levels of IGFBPs are modulated by $\mathrm{E}_{2}{ }^{41}$ IGF signaling plays a role in growth and survival of prostatic ${ }^{42}$ and uterine ${ }^{43}$ epithelia, and IGFBPs antagonize IGF signaling. ${ }^{44}$ Thus, IGFBPs are possible mediators of stromal-epithelial interactions in prostatic and uterine epithelial apoptosis. In prostate, castration increases mRNA levels of transforming growth factor (TGF)- $\beta$ s. ${ }^{45}$ TGF- $\beta$ s are known to be produced by prostatic stromal cells, and their receptors are expressed in prostatic epithelium. ${ }^{46,47}$ Transcripts for TGF- $\beta-1,-2,-3$ and their type-II receptors are upregulated in the mouse uterus after $E_{2}$ withdrawal, and administration of $P_{4}$ inhibits this up-regulation of mRNA for TGF- $\beta$ s. ${ }^{48}$ TGF- $\beta$ s are known to induce cell death in many different cell types including prostatic and uterine epithelia. ${ }^{49,50}$ Therefore, TGF- $\beta$ s are also candidates as paracrine mediators of apoptotic (death) signaling. Epithelial apoptosis in uterus and prostate may be regulated by a balance of these two possible mechanisms (Figure 5A,B). A subtle change in the balance of survival/death signaling may determine the fate of epithelial cells.

Prostatic and uterine stromal tissue consists of many different cell types. The stromal cell types that are the direct target of androgen and progesterone in the regulation of epithelial apoptosis is not clear. Castration of mature male rats results in a rapid reduction of blood flow in VP coinciding with the appearance of TUNEL-positive vascular endothelial and stromal cells. ${ }^{51}$ This reduction in the blood flow precedes prostatic epithelial apoptosis in VP. ${ }^{51} \mathrm{P}_{4}$ also regulates proliferation of the spiral arteries in endometrial stroma of primates. ${ }^{39}$ These studies suggest that action of androgen and $\mathrm{P}_{4}$ on the prostate and uterus, respectively, may involve blood vessel integrity and thus, regulation of blood flow. Vascular endothelial growth factor (VEGF) may be a mediator of androgen action on prostate blood flow. Exogenous androgen given to long-term castrated rats increases the level of vascular endothelial growth factor (VEGF) in VP. ${ }^{52}$

It has been tacitly assumed that activation of the molecular machinery of apoptosis elicited by androgen deprivation is due to failure to maintain ligand occupancy of the AR within the epithelial cells themselves. By this reasoning it is presumed that the occupancy status of the epithelial AR plays a key role in regulating the molecular machinery required for epithelial apoptosis. Our results demonstrate definitely that this is not the case. Epithelial $A R$ is not required to elicit prostatic epithelial apoptosis 


\section{A. prostatic tissue recombinant}

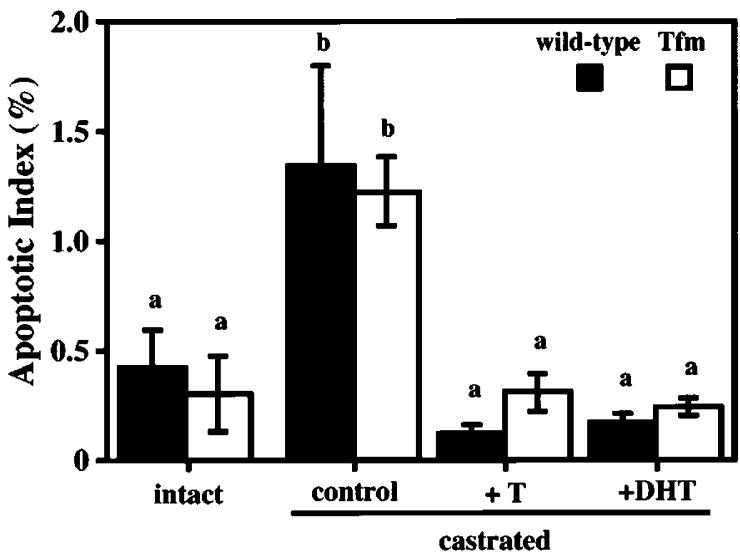

\section{B. uterine tissue recombinant}

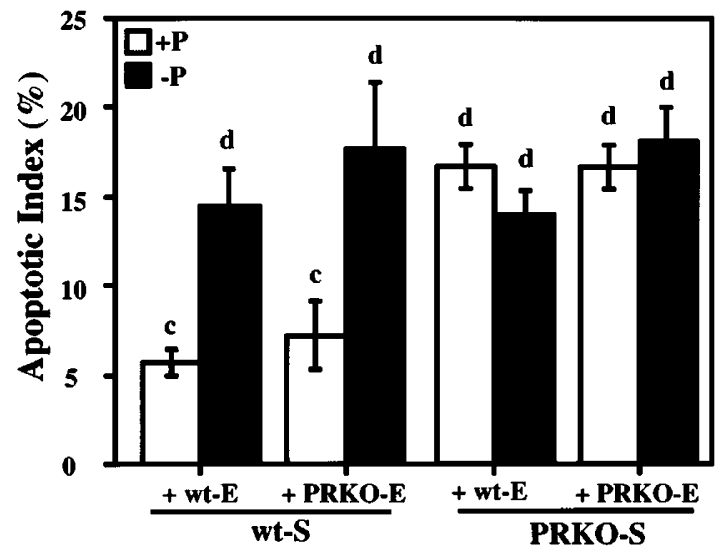

Figure 4 Epithelial apoptotic index in prostatic and uterine tissue recombinants. (A) Prostatic tissue recombinants. (b) is significantly higher than $(\mathrm{a})(P<0.05)$. (B) uterine tissue recombinants. (d) is significantly higher than (c) $(P<0.05)$

A

\section{Epithelium}

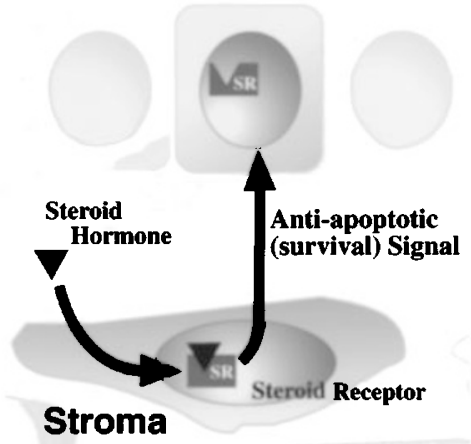

$\mathbf{A}^{\prime}$

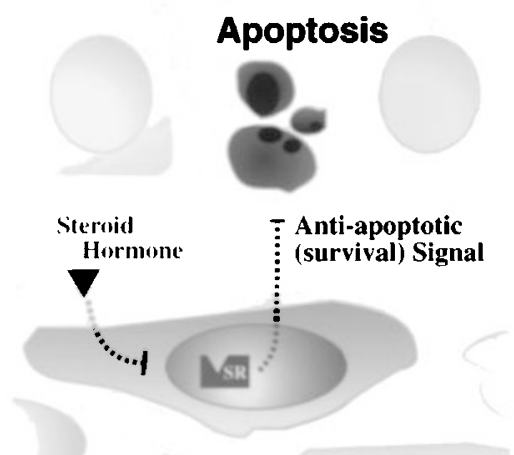

B

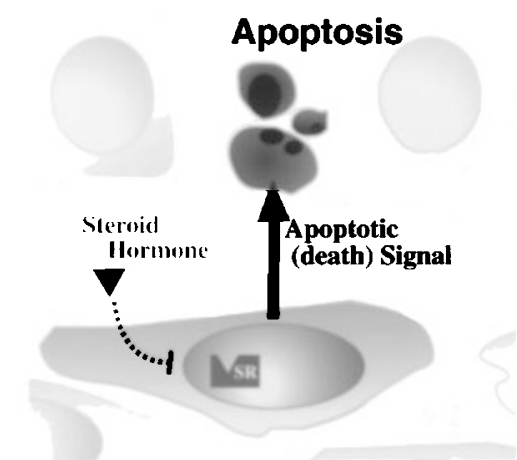

Figure 5 Models of paracrine mechanisms of uterine and prostatic epithelial apoptosis. (A) In presence of steroid hormones, steroid hormone binds to stromal steroid receptor, and the ligand occupied receptor activates signaling pathway to maintain epithelial cells. Even though epithelial steroid receptors are expressed, they are not involved in this signaling pathway. $\left(\mathbf{A}^{\prime}\right)$ As the tissue steroid level is depleted, stromal production of the epithelial survival signal decreases, and epithelial cells undergo apoptosis (B) In response to a reduced steroid hormone level, stroma generates death signals which induce epithelial apoptosis

triggered by androgen deprivation. One of the intracellular regulators of apoptosis is the bcl-2/bax ratio, which changes after castration in epithelium of rat ventral prostate. ${ }^{53}$ Castration of mature male rats also induces expression of transglutaminase ${ }^{54}$ and $c-f o s^{55}$ in the epithelium of rat ventral prostate. In the prostate these intracellular regulators and effectors for epithelial apoptosis must be regulated by androgen via stromal AR through a paracrine mechanism.

We observed that the epithelial apoptotic index of ventral and dorsolateral prostates in the rat is significantly higher than that of the mouse at 3 days after castration. The epithelium in rUGM+wt-mBLE prostatic tissue recombinants mostly shows a dorsolateral prostatic phenotype as assessed by expression of secretory protein specific for DLP. ${ }^{24}$ The prostatic tissue recombinants analyzed in this study were heterospecific (epithelium=mouse, mesenchyme=rat). Epithelial apoptotic index in rUGM+mBLE prostatic tissue recombinants was lower than that of rat DLP and higher than that of mouse DLP. Thus, the level of prostatic epithelial apoptosis may be determined by the origin and phenotype of both stromal and epithelial tissues, even though the kinetic pattern of apoptosis is similar in both species.

Our tissue recombination studies with steroid receptor null mutants have revealed the importance of paracrine mechanisms in steroid actions that regulate growth and differentiation in reproductive organs. ${ }^{56-58}$ This study emphasizes the importance of paracrine mechanisms in steroid hormone regulation of epithelial apoptosis in male and female reproductive tracts. In both male and female reproductive tracts (different systems) androgen and progesterone (different steroid hormones) elicit their antiapoptotic effect via stromal receptors. These data, therefore, strongly suggest general mechanism, that for steroid target organs, hormones regulate epithelial apoptosis via paracrine mechanisms involving stromal-epithelial tissue interactions. Future studies on regulation of the machinery of apoptosis must take into account these paracrine mechanisms. 


\section{Materials and Methods}

\section{Animals}

All animals were maintained in accordance with the NIH Guide for Care and Use of Laboratory Animals, and all procedures described here were approved by the UCSF. Mice were maintained under controlled temperature and lighting conditions during the experiment, and were given food and water ad libitum. Adult athymic nude mice, adult male and time-pregnant female Sprague-Dawley rats were purchased from Charles River (Wilmington, MA, USA). AR null male mice (Tfm male) were bred in our laboratory in a colony from breeding pairs (purchased from Jackson Laboratory). ${ }^{24}$ The affected Tfm males were identified by the presence of testis and female external genitalia. PRKO mice were produced by breeding heterozygous males and females, and genotypes of pups were determined by PCR as described before. ${ }^{59}$

\section{Tissue separation, recombination and grafting}

Details of prostatic ${ }^{24}$ and uterine ${ }^{18}$ tissue recombination have been described, previously. For prostatic tissue recombination, bladder epithelium from neonatal or adult wild-type and Tfm male mice was combined with urogenital sinus mesenchyme from gestation 18 dayold embryonic rats. For uterine tissue recombination, uteri from neonatal PRKO and wild-type litter-mate mice (days 3-10) were used. Female athymic mice were used as hosts for uterine tissue recombinants, and male athymic mice were used as hosts for prostatic tissue recombinant (Charles River, Wilmington, MA, USA)

\section{Hormone treatment and castration}

The experimental design to study prostatic epithelial apoptosis is illustrated in Figure 6A. Prostatic tissue recombinants were grown under the kidney capsule of male athymic nude mice for a month. After 1 month, some hosts were sacrificed to collect tissue recombinants at time zero as a control group, while others were castrated. Three days prior to the castration, $20 \mathrm{mg}$ of T or DHT pellet were subcutaniously implanted into some of the hosts. Three days after castration tissue samples were collected. Pellets were made in our laboratory from $T$ (Sigma) and DHT (Sigma) powder with a pellet press (Parr Instrument Co., Moline, IL, USA).

To study uterine epithelial apoptosis, a hormone treatment protocol described by Terada et $a l^{p}$ was utilized with modifications. The experimental design is illustrated in Figure 6B. Approximately 4 weeks after grafting, all hosts were ovariectomized and kept for another 2 weeks to allow establishment of a hormone deprived state. Two weeks after ovariectomy, daily dosages of $1 \mu \mathrm{g} \mathrm{E}_{2}$ (Sigma, St. Louis, MO, USA) was given to all hosts subcutaneously in $0.1 \mathrm{ml}$ of vehicle for 3 days to stimulate uterine epithelial proliferation thus mimicking the $E_{2}$ surge at the proestrus/estrus. $\mathrm{E}_{2}$ was dissolved in $0.9 \% \mathrm{NaCl}, 0.4 \%$ Polysorbate 80 (Sigma), 0.5\% carboxymethylecellose 80 (Sigma), and $0.9 \%$ benzyl alcohol 80 (Sigma) as described. ${ }^{6,7}$ From days 4 to 6 , $2 \mathrm{mg}$ progesterone $\left(\mathrm{P}_{4}\right)$ (Steroids Inc., Wilton, $\mathrm{NH}, \mathrm{USA}$ ) in $0.1 \mathrm{ml}$ peanut oil (Sigma), or $0.1 \mathrm{ml}$ oil alone were given intraperitoneally. Twenty-four hours after the last hormone injection, host animals were sacrificed to harvest tissue samples.

\section{Immunohistochemistry and apoptosis detection}

Anti-human PR rabbit polyclonal antibody was purchased from DAKO (Carpenteria, CA). Anti-human AR was purchased from Affinity Bio Reagents (Golden, CO, USA). Tissues were fixed with $4 \%$ paraformaldehyde and processed into paraffin, and then sectioned

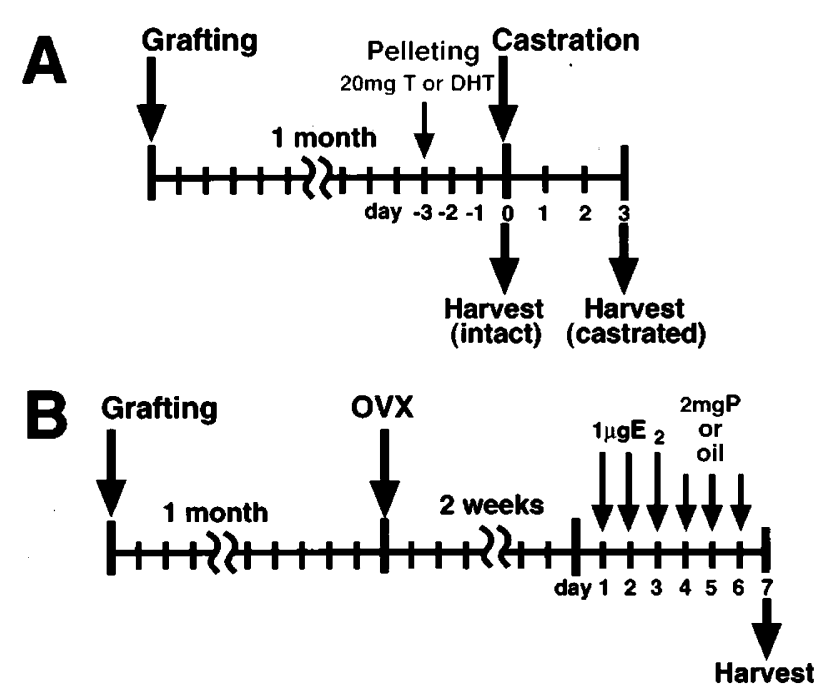

Figure 6 Time lines for experiment protocol. (A) Protocol for induction of prostatic epithelial apoptosis. Prostatic tissue recombinants were grafted under the renal capsule of adult male athymic nude mice. After 1 month, some hosts were sacrificed to collect tissue recombinants at time zero as a control group, while others were castrated. Three days prior to the castration, $20 \mathrm{mg} T$ or DHT pellets were subcutaneously implanted into some hosts. Three days after castration tissue samples were collected. (B) Protocol for progesterone treatment for female mice. Uterine tissue recombinants were grafted under the renal capsule of adult female athymic nude mice. All hosts were ovariectomized at approximately 1 month after grafting, and 2 weeks after the ovariectomy, all hosts were given $1 \mu \mathrm{g} \mathrm{E}_{2}$ daily for 3 days (days $1-3$ ). After three injections of $E_{2}$, hosts were treated with $2 \mathrm{mg} /$ day of progesterone $\left(\mathrm{P}_{4}\right)$ or oil for 3 days (days $4-6$ ), and $24 \mathrm{~h}$ after the last hormone injection, tissue recombinants and host reproductive tracts were collected

at $6 \mu \mathrm{m}$. Slides were deparaffinized, re-hydrated and heated in $10 \mathrm{mM}$ citrate buffer ( $\mathrm{pH} 6.0)$ by microwave. Sections were incubated with primary antibody overnight. Immunoreactivity was developed by Vectorstain Elite ABC kit (Vector Laboratories Inc., Burlingame, CA, USA). ApoTag kit (Oncor Co., Gaithersburg, MD, USA) was used to detect 3'-hydroxyl termini of DNA in situ (TUNEL assay).

\section{Apoptotic index}

For prostate and prostatic tissue recombinants, since counting apoptotic bodies in H\&E stained sections was technically difficult due to small number of apoptotic cells, positive and negative cells for TUNEL staining were counted to determine epithelial apoptotic index. For the apoptotic index of prostatic epithelium, propidiumiodidecounter stained epithelial cells were counted under a fluorescent microscope in randomly selected fields. Cells positive for TUNEL staining were counted in the same field. At least 10 fields from five to 33 prostate or tissue recombinants from at least 3 independent experiments were analyzed (minimum 2000 cells/group). For uterus and uterine tissue recombinants, epithelial apoptotic index was determined by counting apoptotic bodies on images of H\&E slides captured with a DC330 camera (Dage-MTI Inc., Michigan City, IN, USA), interfaced with a PowerBase 200 computer (Power Computing, Round Rock, TX, USA). At least 2000 epithelial cells in 4-33 uterine tissue recombinants from 3 to 5 independent experiments were counted for each group, and in total 351 images from 24 nude mouse hosts and 85 tissue recombinants were analyzed. The result is analyzed by the factorial-ANOVA and Fisher's protected least significant difference (PLSD) tests. 


\section{Acknowledgements}

We thank Dr. Simon W Hayward (Department of Urology, University of California San Francisco, USA) for critical reading of the manuscript. This work was supported by NIH Grants AG-13784, AG-15500, AG-16870, CA 89520, DK 52645, DK 47517 and VA REAP.

\section{References}

1. Kerr JF and Searle J (1973) Deletion of cells by apoptosis during castrationinduced involution of the rat prostate. Virchows Arch. B. Cell Pathol. 13: 87-102

2. Sandow BA, West NB, Norman RL and Brenner RM (1979) Hormonal control of apoptosis in hamster uterine luminal epithelium. Am. J. Anat. 156: 15-35

3. Hopwood D and Levison DA (1976) Atrophy and apoptosis in the cyclical human endometrium. J. Pathol. 119: 159-166

4. Isaacs JT, Furuya Y and Berges R (1994) The role of androgen in the regulation of programmed cell death/apoptosis in normal and malignant prostatic tissue. Semin. Cancer Biol. 5: 391-400

5. Colombel M, Radvanyi F, Blanche M, Abbou C, Buttyan R, Donehower LA, Chopin D and Thiery JP (1995) Androgen suppressed apoptosis is modified in p53 deficient mice. Oncogene 10: 1269-1274

6. Martin L, Finn CA and Carter J (1970) Effects of progesterone and oestradiol-17 beta on the luminal epithelium of the mouse uterus. J. Reprod. Fertil. 21: $461-$ 469

7. Terada N, Yamamoto R, Takada T, Miyake T, Terakawa N, Wakimoto $H$, Taniguchi H, Li W, Kitamura Y and Matsumoto K (1989) Inhibitory effect of progesterone on cell death of mouse uterine epithelium. J. Steroid Biochem. 33: 1091-1096

8. Sato T, Fukazawa Y, Kojima H, Enari M, Iguchi T and Ohta Y (1997) Apoptotic cell death during the estrous cycle in the ratuterus and vagina. Anat. Rec. 248:76-83

9. Evans RM (1988) The steroid and thyroid hormone receptor superfamily. Science 240: 889-895

10. Prins GS, Birch L and Greene GL (1991) Androgen receptor localization in different cell types of the adult rat prostate. Endocrinology 129: 3187-3199

11. Tibbetts TA, Mendoza-Meneses M, O'Malley BW and Conneely OM (1998) Mutual and intercompartmental regulation of estrogen receptor and progesterone receptor expression in the mouse uterus. Biol. Reprod. 59: 1143-1152

12. Uchima F-DA, Edery M, Iguchi T, Larson L and Bern HA (1987) Growth of mouse vaginal epithelial cells in culture: Functional integrity of the estrogen receptor system and failure of estrogen to induce proliferation. Cancer Lett. 35: 227-235

13. McKeehan WL, Adams PS and Rosser MP (1984) Direct mitogenic effects of insulin, epidermal growth factor, glucocorticoid, cholera toxin, unknown pituitary factors and possibly prolactin, but not androgen, on normal rat prostate epithelial cells in serum-free, primary cell culture. Cancer Res. 44: 1998-2010

14. Cooke PS, Uchima F-DA, Fujii DK, Bern HA and Cunha GR (1986) Restoration of normal morphology and estrogen responsiveness in cultured vaginal and uterine epithelia transplanted with stroma. Proc. Natl. Acad. Sci. USA 83: 2109-2113

15. Sugimura Y, Cunha GR and Bigsby RM (1986) Androgenic induction of deoxyribonucleic acid synthesis in prostatic glands induced in the urothelium of testicular feminized (Tfm/y) mice. Prostate 9: 217-225

16. Cooke P, Buchanan D, Young P, Setiawan T, Brody J, Korach K, Taylor J, Lubahn D and Cunha G (1997) Stromal estrogen receptors (ER) mediate mitogenic effects of estradiol on uterine epithelium. Proc. Nat'l. Acad. Sci. USA 94: $6535-6540$

17. Buchanan DL, Kurita T, Taylor JA, Lubahn DB, Cunha GR and Cooke PS (1998) Role of stromal and epithelial estrogen receptors in vaginal epithelial proliferation, stratification, and cornification. Endocrinology 139: 4345-4352

18. Kurita T, Young P, Brody JR, Lydon JP, O'Malley BW and Cunha GR (1998) Stromal progesterone receptors mediate the inhibitory effects of progesterone on estrogen-induced uterine epithelial cell deoxyribonucleic acid synthesis. Endocrinology 139: 4708-4713

19. Buchanan DL, Setiawan T, Lubahn DB, Taylor JA, Kurita T, Cunha GR and Cooke PS (1999) Tissue compartment-specific estrogen receptor participation in the mouse uterine epithelial secretory response. Endocrinology 140: 484-491

20. Kurita T, Lee K, Cooke PS, Lydon JP and Cunha GR (2000) Paracrine regulation of epithelial progesterone receptor and lactoferrin by progesterone in the mouse uterus. Biol. Reprod. 62: $831-838$
21. Kurita T, Lee K, Cooke PS, Taylor JA, Lubahn DB and Cunha GR (2000) Paracrine regulation of epithelial progesterone receptor by estradiol in the mouse female reproductive tract. Biol. Reprod. 62: 821-830

22. Cunha GR and Chung LWK (1981) Stromal-epithelial interactions: I. Induction of prostatic phenotype in urothelium of testicular feminized ( $\mathrm{Tfm} / \mathrm{y})$ mice. J. Steroid Biochem. 14: 1317-1321

23. Cunha GR, Reese BA and Sekkingstad M (1980) Induction of nuclear androgenbinding sites in epithelium of the embryonic urinary bladder by mesenchyme of the urogenital sinus of embryonic mice. Endocrinology 107: 1767-1770

24. Donjacour AA and Cunha GR (1993) Assessment of prostatic protein secretion in tissue recombinants made of urogenital sinus mesenchyme and urothelium from normal or androgen-insensitive mice. Endocrinology 131: 2342-2350

25. Bhatia-Gaur R, Donjacour AA, Sciavolino PJ, Kim M, Desai N, Young P, Norton CR, Gridley T, Cardiff RD, Cunha GR, Abate-Shen C and Shen MM (1999) Roles for Nkx3.1 in prostate development and cancer. Genes Dev. 13: 966-977

26. Jo T, Terada N, Saji F and Tanizawa O (1993) Inhibitory effects of estrogen, progesterone, androgen and glucocorticoid on death of neonatal mouse uterine epithelial cells induced to proliferate by estrogen. J. Steroid Biochem. Mol. Biol. 46: $25-32$

27. Dürnberger $\mathrm{H}$ and Kratochwil K (1980) Specificity of tissue interaction and origin of mesenchymal cells in the androgen response of the embryonic mammary gland. Cell 19: 465-471

28. Roberts LM, Hirokawa Y, Nachtigal MW and Ingraham HA (1999) Paracrinemediated apoptosis in reproductive tract development. Dev. Biol. 208: 110-122

29. Rawson CL, Loo DT, Duimstra JR, Hedstrom OR, Schmidt EE and Barnes DW (1991) Death of serum-free mouse embryo cells caused by epidermal growth factor deprivation. J. Cell Biol. 113: 671-680

30. Taylor TB and Ramsdell JS (1993) Transforming growth factor-alpha and its receptor are expressed in the epithelium of the rat prostate gland. Endocrinology 133: $1306-1311$

31. Hiramatsu M, Kashimata M, Minami N, Sato A and Murayama M (1988) Androgenic regulation of epidermal growth factor in the mouse ventral prostate. Biochem. Int. 17: 311-317

32. St-Arnaud R, Poyet P, Walker P and Labrie F (1988) Androgens modulate epidermal growth factor receptor levels in the rat ventral prostate. Mol. Cell Endocrinol. 56: 21-27

33. Huet-Hudson YM, Chakraborty C, De SK, Suzuki Y, Andrews GK and Dey SK (1990) Estrogen regulates the synthesis of epidermal growth factor in mouse uterine epithelial cells. Mol. Endocrinol. 4: 510-523

34. Zhang Z, Funk C, Glasser SR and Mulholland J (1994) Progesterone regulation of heparin-binding epidermal growth factor-like growth factor gene expression during sensitization and decidualization in the rat uterus: effects of the antiprogestin, ZK 98.299. Endocrinology 135: 1256-1263

35. Ghahary A, Chakrabarti S and Murphy LJ (1990) Localization of the sites of synthesis and action of insulin-like growth factor-I in the rat uterus. Mol Endocrinol. 4: 191-195

36. Westley BR and May FE (1994) Role of insulin-like growth factors in steroid modulated proliferation. J. Steroid Biochem. Mol. Biol. 51: 1-9

37. Richards RG, DiAugustine RP, Petrusz P, Clark GC and Sebastian J (1996) Estradiol stimulates tyrosine phosphorylation of the insulin-like growth factor-1 receptor and insulin receptor substrate- 1 in the uterus. Proc. Natl. Acad. Sci. USA 93: $12002-12007$

38. Rider V and Psychoyos A (1994) Inhibition of progesterone receptor function results in loss of basic fibroblast growth factor expression and stromal cell proliferation during uterine remodelling in the pregnant rat. J. Endocrinol. 140: $239-249$

39. Koji T, Chedid M, Rubin JS, Slayden OD, Csaky KG, Aaronson SA and Brenner RM (1994) Progesterone-dependent expression of keratinocyte growth factor mRNA in stromal cells of the primate endometrium: keratinocyte growth factor as a progestomedin. J. Cell Biol. 125: 393-401

40. Nickerson T, Pollak M and Huynh $\mathrm{H}$ (1998) Castration-induced apoptosis in the rat ventral prostate is associated with increased expression of genes encoding insulin-like growth factor binding proteins 2,3,4 and 5. Endocrinology 139: $807-$ 810

41. Molnar P and Murphy LJ (1994) Effects of oestrogen on rat uterine expression of insulin-like growth factor-binding proteins. J. Mol. Endocrinol. 13: 59-67 
42. Cohen P, Peehl DM, Lamson G and Rosenfeld RG (1991) Insulin-like growth factors (IGFs), IGF receptors, and IGF-binding proteins in primary cultures of prostate epithelial cells. J. Clin. Endocrinol. Metab. 73: 401-407

43. Shiraga M, Takahashi S, Miyake T, Takeuchi S and Fukamachi H (1997) Insulinlike growth factor-I stimulates proliferation of mouse uterine epithelial cells in primary culture. Proc. Soc. Exp. Biol. Med. 215: 412-417

44. Lee PD, Giudice LC, Conover CA and Powell DR (1997) Insulin-like growth factor binding protein-1: recent findings and new directions. Proc. Soc. Exp. Biol. Med. 216: $319-357$

45. Kyprianou N and Isaacs JT (1989) Expression of transforming growth factor-beta in the rat ventral prostate during castration-induced programmed cell death. Mol. Endocrinol. 3: 1515-1522

46. Kyprianou $\mathrm{N}$ and Isaacs JT (1988) Identification of a cellular receptor for transforming growth factor-beta in rat ventral prostate and its negative regulation by androgens. Endocrinology 123: 2124-2131

47. Timme TL, Truong LD, Merz VW, Krebs T, Kadmon D, Flanders KC, Park SH and Thompson TC (1994) Mesenchymal-epithelial interactions and transforming growth factor-beta expression during mouse prostate morphogenesis. Endocrinology 134: 1039-1045

48. Wada K, Nomura S, Morii E, Kitamura Y, Nishizawa Y, Miyake A and Terada N (1996) Changes in levels of mRNAs of transforming growth factor (TGF)-beta1, beta2, -beta3, TGF-beta type II receptor and sulfated glycoprotein-2 during apoptosis of mouse uterine epithelium. J. Steroid Biochem. Mol. Biol. 59: $367-$ 375

49. Martikainen P, Kyprianou N and Isaacs JT (1990) Effect of transforming growth factor-beta 1 on proliferation and death of rat prostatic cells. Endocrinology 127: 2963-2968

50. Rotello RJ, Lieberman RC, Purchio AF and Gerschenson LE (1991) Coordinated regulation of apoptosis and cell proliferation by transforming growth factor beta 1 in cultured uterine epithelial cells. Proc. Natl. Acad. Sci. USA 88: 3412-3415

51. Shabsigh A, Chang DT, Heitjan DF, Kiss A, Olsson CA, Puchner PJ and Buttyan $R$ (1998) Rapid reduction in blood flow to the rat ventral prostate gland after castration: preliminary evidence that androgens influence prostate size by regulating blood flow to the prostate gland and prostatic endothelial cell survival. Prostate 36: 201-206
52. Joseph IB, Nelson JB, Denmeade SR and Isaacs JT (1997) Androgens regulate vascular endothelial growth factor content in normal and malignant prostatic tissue. Clin. Cancer Res. 3: 2507-2511

53. Perlman H, Zhang X, Chen MW, Walsh Kand Buttyan R (1999) An elevated bax/ bcl-2 ratio corresponds with the onset of prostate epithelial cell apoptosis. Cell Death Differ. 6: 48-54

54. Cummings M (1996) Apoptosis of epithelial cells in vivo involves tissue transglutaminase upregulation. J. Pathol. 179: 288-293

55. Feng Z, Joos HJ, Vallan C, Muhlbauer R, Altermatt HJ and Jaggi R (1998) Apoptosis during castration-induced regression of the prostate is Fos dependent. Oncogene 17: 2593-2600

56. Cunha GR, Hayward SW, Hom YK, Donjacour AA, Kurita T, Cooke PS and Lubahn DB (1998) Growth factors as mediators of stromal-epithelial interactions in steroid hormone target organs. In Hormones and growth factors in development and neoplasia, Dickson RB and Salomon DS, eds. New York: Wiley-Liss, Inc., pp. 207-228

57. Cooke PS, Buchanan DL, Kurita T, Lubahn DB and Cunha GR (1998) Stromalepithelial cell communication in the female reproductive tract. In Contemporary Endocrinology, 9. Endocrinology of pregnancy, Bazer FW, eds Totowa, New Jersey, USA: Humana Press Inc. pp. 491-506

58. Cunha GR, BoutinEL, Turner Tand Donjacour AA (1992) Role of mesenchyme in the development of the urogenital tract. In Chemically-Induced Alterations in Sexual and Functional Development: The Wildlife/Human Connection, Colborn $\mathrm{T}$ and Clement $\mathrm{C}$, eds. Princeton: Princeton Scientific Publishing Co., Inc., pp. $85-106$

59. Lydon JP, DeMayo FJ, Funk CR, Mani SK, Hughes AR, Montgomery Jr CA, Shyamala G, Conneely OM and O'Malley BW (1995) Mice lacking progesterone receptor exhibit pleiotropic reproductive abnormalities. Genes Dev. 9: 22662278 